\title{
ACÚMULO E EXPORTAÇÃO DE NUTRIENTES EM BETERRABA
}

\author{
Accumulation and exportation of nutrients in beet crop
}

\author{
Leilson Costa Grangeiro ${ }^{1}$, Maria Zuleide de Negreiros², Brígida Savana de Souza ${ }^{3}$, Pascalle Escóssia de Azevêdo \\ Stênio Lima de Oliveira ${ }^{5}$, Maria Aparecida de Medeiros $^{6}$
}

\begin{abstract}
RESUMO
O objetivo do presente trabalho foi determinar o acúmulo e exportação de nutrientes pela cultura da beterraba em condições de altas temperaturas e luminosidade. O delineamento experimental utilizado foi em blocos casualizados completos com quatro repetições, sendo os tratamentos constituídos pelas épocas de coleta de plantas (20, 30, 40, 50 e 60 dias após semeadura). Em cada coleta foram utilizadas quatro plantas por repetição. O máximo acúmulo de massa seca ocorreu aos $60 \mathrm{DAS}$, sendo de 21,35 g/planta. A maior demanda de nutriente aconteceu no período de 50 a 60 DAS para N e Mg, 30 a 50 DAS para P, 30 a 40 para K e 40 a 50 DAS para $\mathrm{Ca}$. A ordem decrescente dos nutrientes acumulados pela beterraba foi: N, K, Mg, Ca e P. As quantidades totais de N, P, K, Ca e Mg exportadas pelas raízes foram respectivamente de 88,0;6,1;93,2;12,1 e 16,8 kg/ha.
\end{abstract}

Termos para indexação: Beta vulgaris, nutrição de plantas, crescimento.

\begin{abstract}
The objective of this research was to determine on field condition the accumulation and exportation of nutrients by beet crop in conditions of high temperatures and radiations intensity. The experimental design was fully randomized blocks, with four replications. The treatments consisted of the sampling times $(20,30,40,50$ and 60 days after sowing (DAS). The maximum accumulation of dry mass occurred at $60 \mathrm{DAS}$, being of $21.35 \mathrm{~g} / \mathrm{plant}$. The period of higher demand for $\mathrm{N}$ and $\mathrm{Mg}$ occurred from 50 to $60 \mathrm{DAS}, 30$ the $50 \mathrm{DAT}$ for P, 30 the 40 for $\mathrm{K}$ and 40 the 50 for $\mathrm{Ca}$. The decreasing order of nutrient accumulation by the beet crop was: N, K, Mg, Ca and P. The roots exported $88.0 \mathrm{~kg} / \mathrm{ha}$ of $\mathrm{N} ; 6.1 \mathrm{~kg} / \mathrm{ha}$ of P; $93.1 \mathrm{~kg} / \mathrm{ha}$ of K; $12.1 \mathrm{~kg} / \mathrm{ha}$ of Ca and 16.8 $\mathrm{kg} / \mathrm{ha}$ of $\mathrm{Mg}$.
\end{abstract}

Index terms: Beta vulgaris, plant nutrition, growth.

(Recebido em 10 de março de 2006 e aprovado em 25 de outubro de 2006)

\section{INTRODUÇÃO}

A beterraba é uma importante espécie olerícola, que apresenta as raízes como o mais importante produto comercial. No Brasil, seu cultivo intensificou-se grandemente com a imigração européia e asiática, sendo cultivadas exclusivamente variedades de mesa, mesmo assim, em pequena escala comercial, quando se compara com tomate, cebola, alho e outras hortaliças mais tradicionais. Nos últimos dez anos pode-se observar um aumento crescente na procura por esta hortaliça, tanto para utilização nas indústrias de conservas e alimentos infantis, como para consumo "in natura" (SOUZA et al., 2003).

As principais regiões produtoras de beterraba estão nos Estados de São Paulo, Minas Gerais e Rio Grande do
Sul, onde encontram-se $42 \%$ das propriedades produtoras dessa hortaliça tuberosa. No Nordeste, seu cultivo é reduzido, pois as temperaturas mais elevadas tendem a reduzir a pigmentação e conseqüentemente a qualidade do produto.

A exemplo de outras olerícolas, a nutrição mineral é um dos fatores que contribuem para a produtividade $\mathrm{e}$ qualidade do produto comercial, dessa forma os nutrientes devem ser aplicados de acordo com as exigências da cultura, nas quantidades e épocas corretas. Uma das ferramentas utilizadas no balanceamento das adubações é a marcha de absorção de nutrientes, expressa sob a forma de curvas em função da idade da planta (NUNES et al., 1981).

\footnotetext{
'Engenheiro Agrônomo, DSc. Professor Adjunto II do Departamento de Ciências Vegetais - Universidade Federal Rural do Semi-Árido - Br 110 , km 47 Cx. P. 137 - 59625-900 - Mossoró,RN - leilson@ufersa.edu.br

'Engenheira Agrônoma, DSc. Professora Associada I do Departamento de Ciências Vegetais - Universidade Federal Rural do Semi-Árido - Br 110, km 47 Cx. P. 137 - 59625-900 - Mossoró, RN - zuleide@ufersa.edu.br

${ }^{3}$ Engenheira Agrônoma, pós-graduanda do curso de Mestrado em Agronomia/Fitotecnia - Universidade Federal Rural do Semi-Árido - Br 110 , km 47 Cx. P. 137 - 59625-900 - Mossoró, RN - brygitesavana@hotmail.com ${ }^{4}$ Engenheira Agrônoma, pós-graduanda do curso de Mestrado em Agronomia/Fitotecnia - Universidade Federal Rural do Semi-Árido - Br 110, km 47 Cx.P. 137 - 59625-900 -Mossoró, RN - pascalleesco@yahoo.com.br

${ }^{5}$ Engenheiro Agrônomo, pós-graduando do curso de Mestrado em Agronomia/Fitotecnia -Universidade Federal Rural do Semi-Árido - Br 110, km 47 Cx. P. 137 - 59625-900 -Mossoró, RN - stenio-_agro@hotmail.com

${ }^{6}$ Engenheira Agrônoma, pós-graduanda do curso de Mestrado em Agronomia/Fitotecnia - Universidade Federal Rural do Semi-Árido - Br 110, km 47 Cx. P.137 - 59625-900 -Mossoró, RN - cida.med@bol.com.br
} 
O conhecimento da quantidade de nutrientes acumuladas na planta, em cada estágio de desenvolvimento, fornece informações importantes que podem auxiliar no programa de adubação das culturas. Deve-se ter consciência, no entanto, que estas curvas refletem o que a planta necessita, e não o que deve ser aplicado, uma vez que se tem que considerar a eficiência de aproveitamento dos nutrientes, que é variável segundo as condições climáticas, o tipo de solo, o sistema de irrigação, o manejo cultural, entre outros fatores. De modo mais efetivo, essas curvas auxiliam no programa de adubação, principalmente na quantidade dos diferentes nutrientes que devem ser aplicados nos distintos estágios físiológicos da cultura (VILLAS-BOAS, 2001).

Com relação à beterraba praticamente não existe informações na literatura, mostrando a exigência nutricional desta cultura. Haag \& Minami (1987), trabalhando com a cultivar Early Wonder, observaram que a extração de nutrientes foi contínua dos 40 dias até a colheita (80 dias), acentuando-se aos 60 dias de idade. A quantidade total extraída de macronutrientes para uma população de 330 000 plantas/ha foi de: $30 \mathrm{~kg} / \mathrm{ha}$ de $\mathrm{N} ; 8 \mathrm{~kg} / \mathrm{ha}$ de $\mathrm{P} ; 75 \mathrm{~kg} / \mathrm{ha}$ de $\mathrm{K} ; 2 \mathrm{~kg} / \mathrm{ha}$ de $\mathrm{Ca}$ e $4 \mathrm{~kg} / \mathrm{ha}$ de $\mathrm{Mg}$.

Nesse contexto, o presente trabalho teve como objetivo determinar o acúmulo e exportação de nutrientes pela cultura da beterraba em condições de altas temperaturas e luminosidade.

\section{MATERIAL E MÉTODOS}

O experimento foi realizado na horta do Departamento de Ciências Vegetais da Universidade Federal Rural do Semi-Árido em Mossoró-RN, no período de janeiro a março de 2005, em solo classificado com o Argissolo Vermelho-amarelo. Da área experimental foram retiradas amostras de solo, cuja análise química, revelou os seguintes resultados: $\mathrm{pH}$ (água) $=7,9 ; \mathrm{P}=157 \mathrm{mg} \mathrm{dm}^{-3}$; $\mathrm{K}=0,3 \mathrm{cmol}_{\mathrm{c}} \mathrm{dm}^{-3} ; \mathrm{Ca}=3,2 \mathrm{cmol}_{\mathrm{c}} \mathrm{dm}^{-3}, \mathrm{Na}=0,32 \mathrm{cmol}_{\mathrm{c}} \mathrm{dm}^{-3}$ $\mathrm{e} \mathrm{Mg}=1,0 \mathrm{cmol}_{\mathrm{c}} \mathrm{dm}^{-3}$.

O município de Mossoró está situado a $18 \mathrm{~m}$ de altitude, a $5^{\circ} 11^{\prime}$ de latitude sul e $37^{\circ} 20^{\prime}$ ' de longitude oeste. O clima da região, segundo a classificação de Köppen, é BSwh', isto é, seco e muito quente, com duas estações climáticas: uma seca que vai geralmente de junho a janeiro, e outra chuvosa, de fevereiro a maio, apresentando temperatura média anual de $27,4^{\circ} \mathrm{C}$, precipitação pluviométrica anual irregular com média de $673 \mathrm{~mm}$ e umidade relativa de 68,9\% (CARMO FILHO et al., 1991).

O delineamento experimental utilizado foi em blocos casualizados completos com quatro repetições, sendo os tratamentos constituídos pelas épocas de coleta de plantas (20, 30, 40, 50 e 60 dias após semeadura). Em cada coleta foram utilizadas quatro plantas por repetição. A unidade experimental foi composta por três fileiras de 10 plantas, espaçadas de $0,30 \mathrm{~m}$ entrelinhas e $0,10 \mathrm{~m}$ entre plantas, com área total de $0,9 \mathrm{~m}^{2}$ por parcela. Por ocasião da coleta, a amostragem era realizada na fileira central.

O preparo do solo constou de uma gradagem, seguida do levantamento dos canteiros. As adubações foram realizadas com base na análise do solo, e segundo a recomendação de Cavalcanti (1998), sendo aplicado em fundação $45 \mathrm{~kg} / \mathrm{ha}$ de $\mathrm{N}$, na forma de uréia, $60 \mathrm{~kg} / \mathrm{ha}$ de $\mathrm{P}_{2} \mathrm{O}_{5}$ na forma de superfosfato simples e $30 \mathrm{~kg} / \mathrm{ha}$ de $\mathrm{K}_{2} \mathrm{O}$, na forma de cloreto de potássio. A adubação de cobertura foi parcelada em duas vezes aos 25 e 45 dias, sendo utilizado $40 \mathrm{~kg} / \mathrm{ha}$ de $\mathrm{N}$ na forma de uréia e $30 \mathrm{~kg} / \mathrm{ha}$ de $\mathrm{K}_{2} \mathrm{O}$ na forma de cloreto de potássio. A beterraba, cultivar Early Wonder foi semeada em covas de aproximadamente $2 \mathrm{~cm}$ de profundidade colocando-se quatro sementes, espaçadas de 0,30 x 0,10 m, e após 14 dias realizou-se o desbaste, deixando a planta mais vigorosa. A irrigação foi realizada através de microaspersores com aplicação de água diária.

As coletas de plantas foram realizadas em períodos pré-estabelecidos, na parte da manhã, para evitar que as plantas murchassem até chegar ao laboratório. As plantas selecionadas em cada coleta deveriam ser competitivas, ou seja, apresentavam as mesmas condições de crescimento das demais, obedecendo ao espaçamento pré-definido e com bom aspecto visual (isentas de pragas e/ou doenças). Em seguida, as plantas eram levadas ao Laboratório de Pós-colheita do Departamento de Ciências Vegetais, onde foram fracionadas em parte aérea e raízes, lavadas e colocadas separadamente, em saco de papel e levadas para secagem em estufa com circulação forçada de ar à temperatura de $65-70^{\circ} \mathrm{C}$, até atingir massa constante. Em função da massa seca das amostras, foi determinado o acúmulo de massa seca da parte aérea (caule + folha) e raiz em cada época de coleta, sendo os resultados expressos em g/planta. Em seguida, as amostras foram processadas em moinho tipo Willey (peneira de $2 \mathrm{~mm}$ ) e acondicionadas em recipientes fechados.

As análises químicas para a determinação dos teores de nutrientes presentes em cada fração foram feitas nos extratos obtidos pela digestão sulfúrica (nitrogênio), nítrico-perclórica (fósforo, potássio, cálcio e magnésio). $\mathrm{O}$ nitrogênio foi quantificado pelo método semi-micro Kjeldahl, fósforo pelo método do complexo fosfo-molíbdico em meio redutor, adaptado por Braga \& Defelipo (1974), 
potássio por fotometria de emissão de chama e cálcio e magnésio por complexometria (EMBRAPA, 1997).

O resultado das análises forneceu as concentrações dos nutrientes (N, P, K, Ca e Mg) e para se determinar a quantidade destes acumulados em cada fração da planta, multiplicou-se a concentração pela massa seca da referida fração, sendo que o acúmulo total na planta foi determinado através da soma do acúmulo das frações para cada nutriente.

Todas as características determinadas foram submetidas à análise de variância utilizando-se o software ESTAT e análise de regressão com o software Tablecurve (JANDEL SCIENTIFIC, 1991).

\section{RESULTADOS E DISCUSSÃO}

\section{Acúmulo de massa seca}

O crescimento da planta, expresso pelo acúmulo de massa seca ao longo do ciclo, inicialmente foi lento até 30 dias após a semeadura (DAS), sendo que ao final do ciclo, a produção estimada de massa seca total foi de 21,35 g/ planta, com uma participação da parte aérea de $52 \%$ e das raízes de $48 \%$ (Figura 1). O maior acúmulo ocorreu no período compreendido entre 50 e $60 \mathrm{DAS}$, quando a taxa de incremento estimada foi de $0,665 \mathrm{~g} /$ planta/dia.

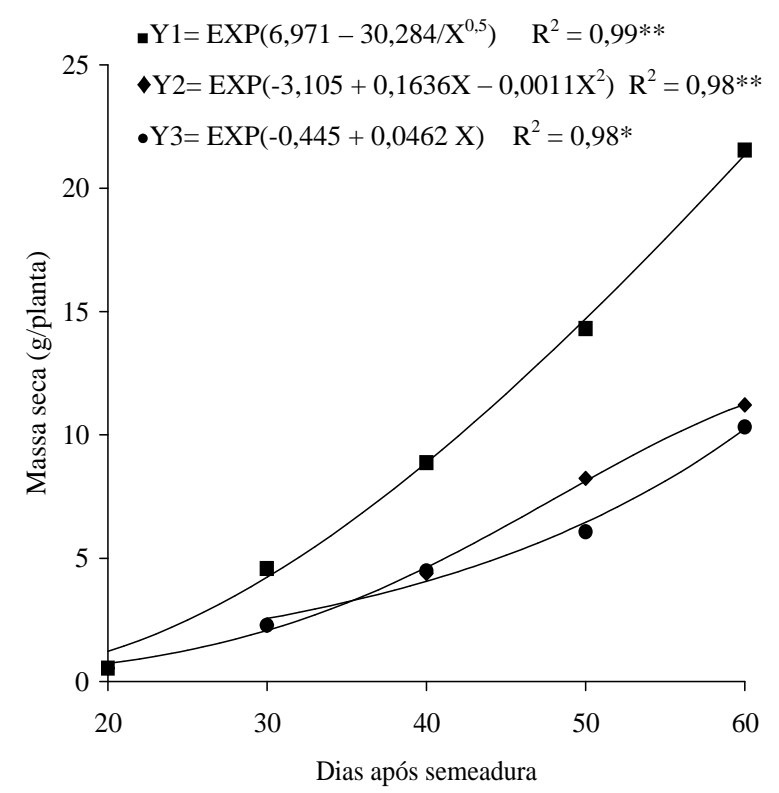

FIGURA 1 - Acúmulo de massa seca total (Y1), parte aérea (Y2) e raízes (Y3) em beterraba, cultivar Early Wonder, Mossoró-RN, UFERSA, 2005.
A parte aérea também apresentou acúmulo crescente de massa seca, sendo observado no período de 40 a 50 DAS o acúmulo máximo, com taxas estimadas de 0,385 g/planta/dia. Nas raízes o máximo acúmulo foi obtido no período de 50 a 60 DAS, quando a taxa foi de $0,387 \mathrm{~g} /$ planta/dia, superior ao da parte aérea no mesmo período. Embora no final do ciclo, a parte aérea tenha contribuído com a maior porcentagem de massa seca acumulada, verificou-se uma redução da taxa de acúmulo média desta em relação às raízes.

Relacionando os dados de acúmulo de matéria seca da parte aérea com o acúmulo de matéria seca de raízes de beterraba, Guimarães et al. (2002) verificaram que houve um grande investimento inicial na parte aérea, logicamente para o estabelecimento dos órgãos responsáveis pela fonte de fotoassimilados. A estabilização do acúmulo de massa seca na parte aérea coincidiu com o acúmulo exponencial de matéria seca nas raízes, que se tornou o grande dreno da planta. A matéria seca nas raízes atingiu praticamente o dobro da matéria seca da parte aérea, ao final da avaliação (98 DAS). Resultados semelhantes foram observados por Nunes et al. (1981) em beterraba açucareira.

Haag \& Minami (1987) avaliaram o crescimento da beterraba através da produção de massa seca e verificaram aumentos na massa seca da parte aérea e de raízes até o final do ciclo da cultura, por volta de 80 dias.

\section{Acúmulo de nutrientes}

\section{Nitrogênio}

O acúmulo máximo total de nitrogênio pela cultivar de beterraba Early Wonder foi de 558,3 mg/planta (186,10 $\mathrm{kg} / \mathrm{ha}$ ), obtida aos 60 DAS, sendo que a parte aérea foi responsável por $52,7 \%$ e as raízes com $47,3 \%$. A maior demanda ocorreu de 50 a 60 DAS, coincidindo com a época de maior acúmulo de massa seca na planta (Figura 2). Esses resultados foram superiores ao encontrados por Haag \& Minami (1987) que para uma população de 330.000 plantas/ ha obtiveram um acúmulo de $30 \mathrm{~kg} / \mathrm{ha}$ de nitrogênio e próximos aos obtidos (150 kg/ha) por Trani et al. (1992), citados por Souza et al. (2003).

O nitrogênio mineral absorvido pelas raízes é assimilado para satisfazer as necessidades de compostos nitrogenados da planta. Segundo Andriolo (1999), na escala do ciclo da cultura, há, portanto, uma ligação entre a absorção de $\mathrm{N}$ e o crescimento em massa seca da planta. Trani et al. (2005) verificaram uma relação linear entre o rendimento de massa seca da parte aérea e de raízes de beterraba com doses aplicadas de nitrogênio. 

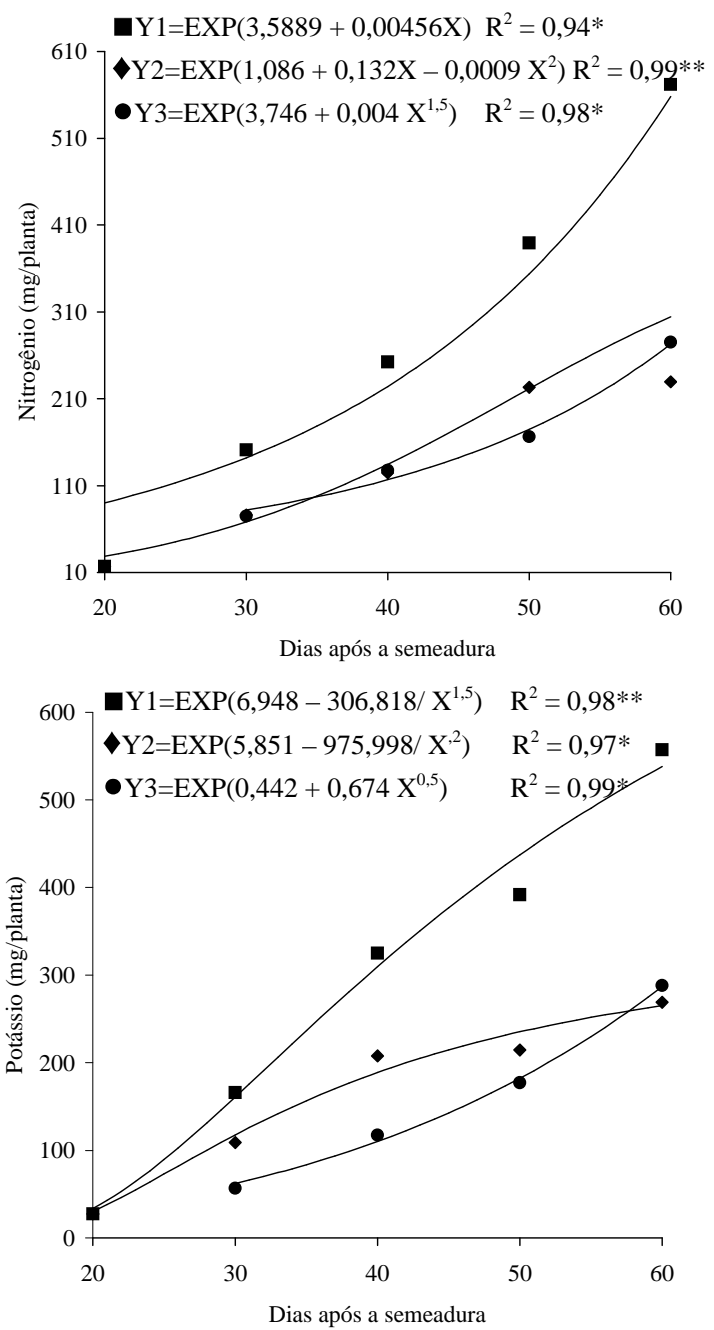
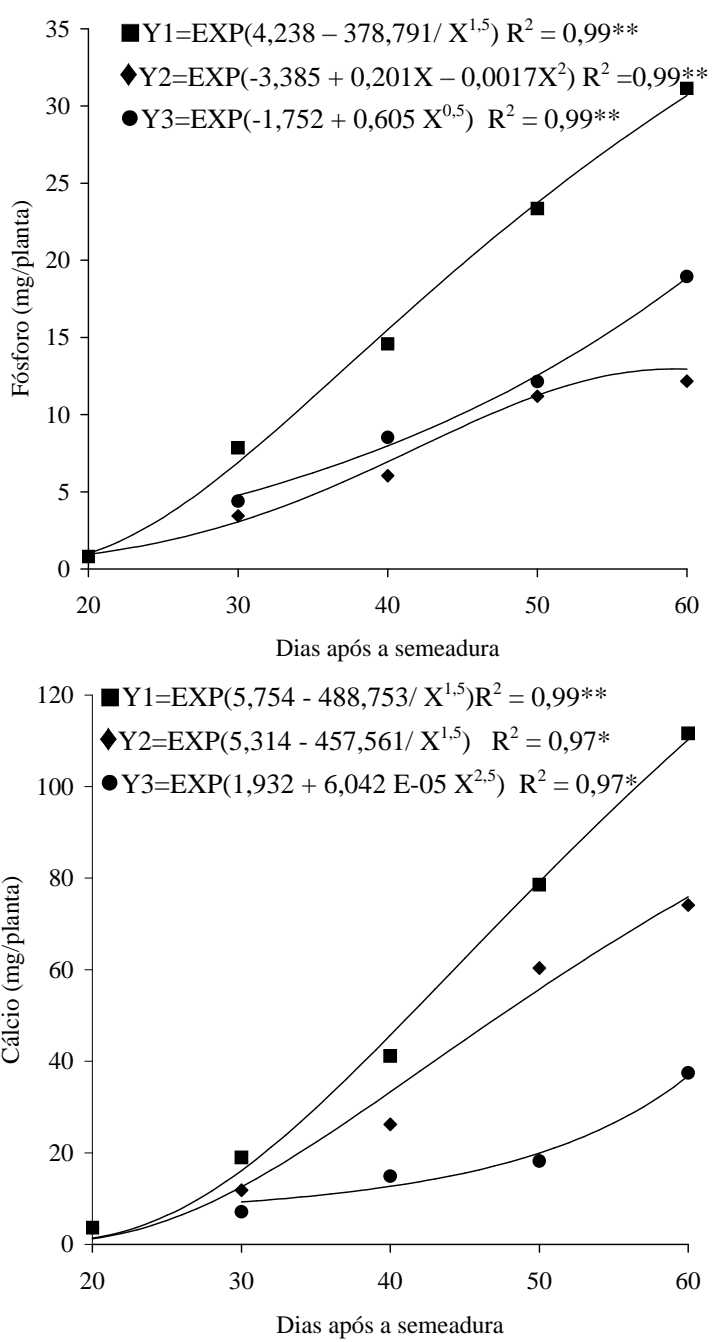

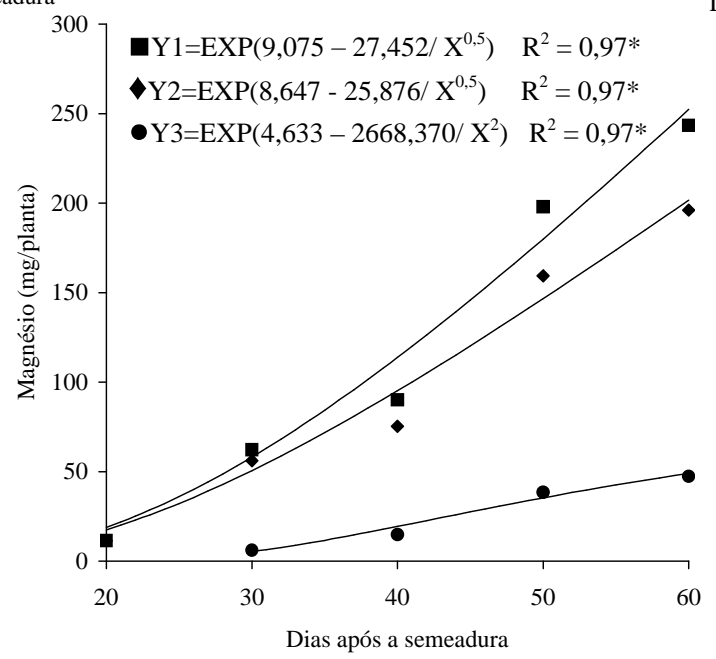

FIGURA 2 - Acúmulo de N, P, K, Ca e Mg, total (Y1), parte aérea (Y2) e raízes (Y3) em beterraba, cultivar Early Wonder. Mossoró-RN, UFERSA, 2005. 
Na parte aérea, a taxa de acúmulo máximo de nitrogênio foi obtido no período de 40 a 50 DAS, sendo de $8,71 \mathrm{mg} / \mathrm{planta} / \mathrm{dia}$, coincidindo também com o maior acúmulo de massa seca na mesma. Já nas raízes, a maior taxa de acúmulo (9,82 $\mathrm{mg} / \mathrm{planta} / \mathrm{dia})$ foi verificada no período de 50 a $60 \mathrm{DAS}$, quando houve um pequeno decréscimo no acúmulo da parte aérea. Embora, em termos de acúmulo total, a parte aérea tenha sido responsável por mais da metade do nitrogênio acumulado pela planta, essa diminuição na taxa de acúmulo ocorrido na mesma, no final do ciclo, demonstra haver certa inversão com relação aos drenos preferenciais da planta.

Trani et al. (1993), ao revisarem os efeitos do nitrogênio na adubação de beterraba, verificaram que são vários os fatores que interferem na sua eficácia. Por exemplo, a resposta à aplicação de nitrogênio em beterraba depende do tipo de solo, da temperatura, da época e maneira de adubação, e da fonte de nitrogênio. Por outro lado, adubações excessivas com $\mathrm{N}$ podem afetar na qualidade da raiz, provocando o acúmulo de glutamina e de PCA, um ácido orgânico que acarreta sabor amargo na beterraba após o cozimento (SOUZA et al., 2003).

\section{Fósforo}

O fósforo foi o nutriente de menor acúmulo pela beterraba, com o máximo de 30,67 mg/planta (10,22 kg/ha), atingido aos 60 DAS. A maior demanda ocorreu no período de 30 a 50 DAS, quando a taxa de acúmulo foi de aproximadamente $0,84 \mathrm{mg} /$ planta/dia (Figura 2). As raízes contribuíram com a maior parte $(59,3 \%)$ em relação à parte aérea $(40,7 \%)$. Na parte aérea, a taxa de acúmulo foi crescente até o período de 40 a 50 DAS, sendo de $0,43 \mathrm{mg} /$ planta/dia. Nas raízes, o comportamento foi semelhante ao nitrogênio, ou seja, a maior demanda aconteceu de 50 a 60 dias. Os valores acumulados de fósforo ficaram próximos daquele obtidos por Haag \& Minami (1987). De uma forma geral, a beterraba não é considerada uma hortaliça exigente em fósforo, encontrando-se na literatura recomendações de adubação variando de 60 até $400 \mathrm{~kg} / \mathrm{ha}$ de $\mathrm{P}_{2} \mathrm{O}_{5}$ (TRANI et al., 2003).

As quantidades de fósforo retiradas do solo pelas hortaliças são geralmente baixas, principalmente quando comparadas com o nitrogênio e o potássio. Entretanto, apesar dessa aparente baixa exigência, os teores desse nutriente na solução do solo, bem como a velocidade do seu restabelecimento na mesma, não são suficientes para atender às necessidades das culturas. Como consequiência, nas adubações é o fósforo que entra em maiores proporções (COUTINHO et al., 1993).

\section{Potássio}

O potássio foi o segundo nutriente mais acumulado pela cultivar de beterraba Early Wonder, com acúmulo máximo de $538 \mathrm{mg} /$ planta $(179,3 \mathrm{~kg} / \mathrm{ha})$, aos 60 DAS, tendo a maior demanda ocorrida no período de 30 a 40 DAS (Figura 2). As participações da parte aérea e raízes foram respectivamente de $48 \%$ e $52 \%$. Diferentemente dos observados por Haag \& Minami (1987) e por Kemmler (1988), citados por Trani et al. (1993), que o obtiveram o potássio como o nutriente de maior acúmulo.

Na parte aérea, as taxas de maiores acúmulos aconteceram até aproximadamente os 40 DAS, com média no período de $7,93 \mathrm{mg} /$ planta/dia. A partir de então, as raízes apresentaram uma maior taxa de acúmulo em relação à parte aérea, com máximo de $10,5 \mathrm{mg} / \mathrm{planta} /$ dia no período de 50 a 60 DAS. Esse comportamento demonstra que as raízes como órgão de armazenamento, são também a partir de certo momento, os drenos preferencias da planta. A beterraba é considerada moderadamente ou bastante exigente em potássio, existindo certa controvérsia entre os autores. Entretanto, são poucos os trabalhos relativos aos efeitos desse nutriente na produção e qualidade dessa hortaliça.

\section{Cálcio}

O acúmulo máximo de cálcio foi de 110,24 mg/planta (36,8 kg/ha), atingido aos 60 DAS. A maior demanda ocorreu no período de 40 a 50 DAS, coincidindo também com o maior acúmulo de massa seca pela planta. A participação da parte aérea foi de $67,1 \%$ e das raízes $32,9 \%$ (Figura 2).

Na parte aérea, a taxa de acúmulo máximo de cálcio foi obtida no período de 40 a 50 DAS, sendo de 2,24 g/ planta/dia, coincidindo também com o maior acúmulo de massa seca na mesma. Já nas raízes, a maior taxa de acúmulo (1,68 g/planta/dia) foi verificada no período de 50 a 60 DAS. Em relação aos outros nutrientes (N, P e K), o acúmulo de cálcio foi bem maior na parte aérea, evidenciando o fato de o cálcio absorvido pela raiz ser translocado para parte aérea e não ser redistribuído dentro da planta, devido a sua baixa mobilidade. Tal fato foi observado por Yorinori (2003) em batata.

O acúmulo total de cálcio obtido no presente trabalho $(36,8 \mathrm{~kg} / \mathrm{ha})$, foi bem superior aos encontrados por Haag \& Minami (1987), quando trabalharam com essa mesma cultivar $(2,0 \mathrm{~kg} / \mathrm{ha})$. Entretanto, foi próximo ao valor (36,0 kg/ha) encontrado por Fersini (1976), citado por Trani et al. (1993). 


\section{Magnésio}

O total acumulado de $\mathrm{Mg}$ na planta foi de 252,37 $\mathrm{mg} /$ planta $(84,1 \mathrm{~kg} / \mathrm{ha})$, com maior demanda no período de 50 a 60 DAS (Figura 2), coincidindo com o maior incremento de massa seca na planta. As participações da parte aérea e raízes foram respectivamente de 80 e $20 \%$. O magnésio, em quantidades maiores que o cálcio, acumula-se preferencialmente na parte aérea; fato semelhante foi verificado em outras hortaliças como em melancia, quando o maior acúmulo foi na parte aérea em relação aos frutos (GRANGEIRO \& CECÍLIO FILHO, 2004, 2005), em batata (YORINORI, 2003) e tomate (FAYAD, 1998). Uma das prováveis causa, para essa maior acumulação do $\mathrm{Mg}$ na parte aérea é que o mesmo faz parte da molécula de clorofila. De acordo com Marschner (1995), dependendo do "status" de $\mathrm{Mg}$ na planta, entre 6 a $25 \%$ do magnésio total está ligado à molécula de clorofila, outros 5 a $10 \%$ estão firmemente ligados a pectatos, na parede celular, ou como sal solúvel, no vacúolo.

\section{Exportação de nutrientes}

No momento da colheita, 60 dias após a semeadura, as raízes correspondiam a $48 \%$ da massa seca da planta. Do total dos nutrientes acumulados pela beterraba, as raízes participaram com 47,3\% de N, 59,3\% de $\mathrm{P}, 52 \%$ de K, 32,9\% de Ca e $20 \%$ de $\mathrm{Mg}$. Os nutrientes $\mathrm{P}$ e K, portanto, acumulam-se preferencialmente nas raízes, enquanto N, Ca e Mg na parte vegetativa. As quantidades totais de $\mathrm{N}, \mathrm{P}, \mathrm{K}, \mathrm{Ca}$ e $\mathrm{Mg}$ exportadas pelas raízes foram de 88,$0 ; 6,1 ; 93,2 ; 12,1$ e $16,8 \mathrm{~kg} \mathrm{ha}^{-1}$, respectivamente (Tabela 1).

TABELA 1 - Exportação de N, P, K, Ca e Mg pelas raízes de beterraba cultivar Early Wonder, Mossoró-RN, UFERSA, 2005.

\begin{tabular}{ccc}
\hline Nutrientes & $\begin{array}{c}\text { Exportação } \\
\text { (kg/ ha)* }\end{array}$ & $\begin{array}{c}\text { Percentagem do } \\
\text { total (\%) }\end{array}$ \\
\hline $\mathrm{N}$ & 88,0 & 47,3 \\
$\mathrm{P}$ & 6,1 & 59,3 \\
$\mathrm{~K}$ & 93,2 & 52,0 \\
$\mathrm{Ca}$ & 12,1 & 32,9 \\
$\mathrm{Mg}$ & 16,8 & 20,0 \\
\hline
\end{tabular}

*Densidade de plantio 333.333 plantas ha $^{-1}$ e produtividade de $30 \mathrm{t} \mathrm{ha}^{-1}$.
As quantidades de nutrientes exportadas pelas raízes, portanto, representam importante componente de perdas de nutrientes do solo, que deverão ser restituídos, enquanto os nutrientes contidos na parte aérea podem ser incorporados ao solo dentro de um programa de reaproveitamento de restos culturais.

\section{CONCLUSÕES}

A cultivar de beterraba Early Wonder apresentou crescimento inicial lento, intensificando-se a partir dos 30 dias após a semeadura;

A massa seca total acumulada máxima por planta foi de $21,35 \mathrm{~g} /$ planta, com uma participação da parte aérea de $52 \%$ e das raízes de $48 \%$;

A maior demanda de nutriente aconteceu no período de 50 a 60 DAS para $\mathrm{N}$ e Mg, 30 a 50 DAS para $\mathrm{P}, 30$ a 40 para K e 40 a 50 DAS para Ca, com máximo acumulado de 558,$3 ; 30,67 ; 538,0 ; 100,24$ e 252,37 mg/planta, respectivamente para $\mathrm{N}, \mathrm{P}, \mathrm{K}, \mathrm{Ca}$ e $\mathrm{Mg}$;

As quantidades totais de $\mathrm{N}, \mathrm{P}, \mathrm{K}, \mathrm{Ca}$ e $\mathrm{Mg}$ exportadas pelas raízes foram de 88,$0 ; 6,1 ; 93,2 ; 12,1$ e 16,8 $\mathrm{kg} \mathrm{ha}^{-1}$, respectivamente.

\section{REFERÊNCIAS BIBLIOGRÁFICAS}

ANDRIOLO, J. L. Fisiologia das culturas protegidas. Santa Maria: UFSM, 1999. 142 p.

BRAGA, J. M.; DEFELIPO, B. V. Determinação espectrofotométrica de fósforo em extratos de solos e plantas. Revista Ceres, Viçosa, v. 113, p. 73-85, 1974.

CARMO FILHO, F. do; ESPÌNOLA SOBRINHO, J.; MAIA NETO, J. M. Dados climatológicos de Mossoró: um município semi-árido nordestino. Mossoró: ESAM, 1991. 121 p. (Coleção Mossoroense, 30).

CAVALCANTI, F. J. de A. Recomendações de adubação para o estado de Pernambuco: $2^{\mathrm{a}}$ aproximação. Recife: IPA, 1998.198 p.

COUTINHO, E. L. M.; NATALE, W.; SOUZA, E. C. A. Adubos e corretivos: aspectos particulares na olericultura. In: FERREIRA, M. E.; CASTELLANE, P. D.; CRUZ, M. C. P. (Coords.). Nutrição e adubação de hortaliças. Jaboticabal: Faculdade de Ciências Agrárias e Veterinárias, 1993. p. 85-140.

EMPRESA BRASILEIRA DE PESQUISA AGROPECUÁRIA. Manual de métodos de análise de solo. 2. ed. Rio de Janeiro: Centro Nacional de Pesquisa de Solos, 1997. 212 p. 
FAYAD, J. A. Absorção de nutrientes, crescimento e produção do tomateiro cultivado em condições de campo e estufa. 1998. 81 f. Dissertação (Mestrado em Agronomia) Universidade Federal de Viçosa, Viçosa, 1998.

GRANGEIRO, L. C.; CECÍlLIO FILHO, A. B. Acúmulo e exportação de macronutrientes pelo híbrido de melancia Tide. Horticultura Brasileira, Brasília, v. 22, n. 1, p. 93-97, 2004.

GRANGEIRO, L. C.; CECÍllO FILHO, A. B. Acúmulo e exportação de nutrientes em melancia sem sementes. Horticultura Brasileira, Brasília, v. 23, n. 3, p. 763-767, 2005.

GUIMARÃES, V. F.; ECHER, M. M.; MINAMI, K. Métodos de produção de mudas, distribuição de matéria seca e produtividade de plantas de beterraba. Horticultura Brasileira, Brasília, v. 20, n. 3, p. 505-509, 2002.

HAAG, H. P.; MINAMI, K. Nutrição mineral de hortaliças: LXIII. requerimento de nutrientes pela cultura da beterraba. Anais da Escola Superior de Agricultura "Luiz de Queiroz", Piracicaba, v. 44, p. 401-407, 1987.

JANDEL SCIENTIFIC. Table curve: curve fitting software. Corte Madera, 1991. 280 p.

MARSCHNER, H. Mineral nutrition of higher plants. San Diego: Academic, 1995. 889 p.
NUNES, M. A.; DIAS, M. A.; GASPAR, A. M.; OLIVEIRA, M. D.; PINTO, E.; CARAPAU, A. L. Análise do crescimento da beterraba sacarina em cultura de primavera. Agricultura Lusitana, [S.1.], v. 40, n. 3, p. 217-240, 1981.

SOUZA, R. J. de; FONTANETTI, A.; FIORINI, C. V. A.; ALMEIDA, K. de. Cultura da beterraba: cultivo convencional e cultivo orgânico. Lavras: UFLA, 2003. 37 p. (Texto acadêmico).

TRANI, P. E.; CANTARELLA, H.; TIVELLI, S. W. Produtividade de beterraba em função de doses de sulfato de amônio em cobertura. Horticultura Brasileira, Brasília, v. 23, n. 3, p. 726-730, 2005.

TRANI, P. E.; FORNASIER, J. B.; LISBÃO, R. S. Nutrição e adubação da beterraba. In: FERREIRA, M. E.; CASTELLANE, P. D.; CRUZ, M. C. P. (Eds.). Nutrição e adubação de hortaliças. Piracicaba: Associação Brasileira para pesquisa da potassa e do fosfato, 1993. p. 429-446.

VILLAS-BOAS, R. L. Doses de nitrogênio para pimentão aplicadas de forma convencional e através da fertirrigação. 123 f. 2001. Tese (Livre docência) - Universidade Estadual Paulista, Botucatu, 2001.

YORINORI, G. T. Curva de crescimento e acúmulo de nutriente pela cultura da batata cv. "Atlantic". 2003. $66 \mathrm{f}$. Dissertação (Mestrado em Agronomia) - Escola Superior de Agricultura Luiz de Queiroz, Piracicaba, 2003. 